\title{
Atypical Transcriptional Regulation and Role of a New Toxin-Antitoxin-Like Module and Its Effect on the Lipid Composition of Bradyrhizobium japonicum
}

\author{
Paul S. Miclea, ${ }^{1}$ Mária Péter, ${ }^{2}$ Gergely Végh, ${ }^{3}$ Gyöngyi Cinege, ${ }^{1}$ Ernö Kiss, ${ }^{1}$ György Váró, ${ }^{3}$ Ibolya Horváth, ${ }^{2}$ \\ and Ilona Dusha ${ }^{1}$ \\ ${ }^{1}$ Institute of Genetics, ${ }^{2}$ Institute of Biochemistry, and ${ }^{3}$ Institute of Biophysics, Biological Research Center, Hungarian Academy \\ of Sciences, P.O.Box 521, H-6701 Szeged, Hungary
}

Submitted 15 October 2009. Accepted 14 January 2010.

\begin{abstract}
A toxin-antitoxin (TA)-like system (designated as bat/bto genes) was identified in Bradyrhizobium japonicum, based on sequence homology and similarities in organization and size to known TA systems. Deletion of the bat/bto module resulted in pleiotropic alterations in cell morphology and metabolism. The generation time of the mutant was considerably decreased in rich media. Atomic force microscopy revealed the modified shape (shorter and wider) and softness of mutant cells. The synthesis of phosphatidylcholine was completely blocked in the mutant bacteria, and vaccenic acid, the predominant fatty acid of membranes of the wild-type cell, was replaced by palmitic acid in the mutant membranes. The mutant bacteria synthesized incomplete lipopolysaccharide molecules. Remarkable changes in the membrane lipid composition may explain the observed morphological alterations and growth properties of the mutant bacteria. The overlapping promoter region of bat/bto and $g l p D$ (coding for the aerobic $s n$-glycerol-3-phosphate dehydrogenase) genes suggests a complex regulation and the involvement of bat/bto in the control of main metabolic pathways and an important role in the maintenance of a normal physiological state of $B$. japonicum. These data reveal new aspects of the role of TA systems in bacteria.
\end{abstract}

Toxin-antitoxin (TA) modules consisting of two partially overlapping genes are ubiquitous among bacteria and archaea (Arcus et al. 2004; Gerdes et al. 2005). TA loci identified on plasmids as well as on chromosomes are characterized by similar genetic organization and regulation. Toxin genes encode proteins that recognize specific targets in the cell, and the protein products of the generally upstream-located antitoxin genes counteract the toxins by forming a complex with them. TA operons are under the negative control of the TA complex, which is able to bind to the promoter region and prevent transcription of the module (Gerdes et al. 2005).

The mechanism of action of TA systems is based on the different stabilities of toxin and antitoxin proteins; unstable antitoxins are degraded faster than stable toxins (Buts et al. 2005; Gerdes et al. 2005; Hayes 2003). The altered ratio of the two components can be induced by starvation, DNA damage, or antibiotics (Christensen et al. 2001; Hazan et al. 2004; Sat et al. 2001). The excess amount of free toxin exerts toxic effects on various cellular targets acting as DNA gyrase inhibitors,

Corresponding author: Ilona Dusha: Telephone: +36(62) 599 675; Fax: +36(62) 433 503; E-mail: dushai@brc.hu site-specific endoribonucleases, ribosome-dependent ribonucleases, or possible riboexonucleases (Arcus et al. 2004; Jensen and Gerdes 1995; Pedersen et al. 2003; Zhang et al. 2003). Plasmid-encoded systems have a clear role in plasmid maintenance by preventing the proliferation of plasmid-free progeny (Gerdes et al. 2005). The physiological function of chromosomally carried systems is still controversial, even in wellcharacterized cases. It has been shown that MazF of Escherichia coli, when activated by various stress conditions, induces significant loss of viability (Amitai et al. 2004; Hazan et al. 2004). Contrary to this observation, ectopic expression of RelE or MazF was shown to decrease cell metabolism, resulting in bacteriostasis rather than a bacteriocidal effect (Pedersen et al. 2002). The induction of the cognate antitoxins neutralized the effect of toxin molecules and cells were able to recover to normal physiology. It is possible, however, that the quasidormant state can either be reversed if stress conditions improve within a short period of time or, alternatively, after a prolonged time cells pass the 'point of no return' and lose the capacity to recover (Amitai et al. 2004). Recently, TA loci of chromosomal locations were also shown to participate in bacterial persistence and biofilm formation (Brooun et al. 2000; Keren et al. 2004; Lewis 2005). Since bacteria generally contain more than one TA module, the possibility that they are all involved in stress response has been investigated. Surprisingly, the absence of five copies of $E$. coli TA modules did not influence cell viability under stressful conditions (Tsilibaris et al. 2007).

The proposed role of TA loci as general stress managers adjusting metabolic rates under varying environmental stimuli may be of special importance during the adaptation of soil bacteria to oligotrophic conditions. In addition, symbiotic nitrogenfixing soil bacteria that develop an intimate interaction with leguminous plants have the ability to adapt and function also within the plant host cells during symbiosis.

The development of symbiotic interactions of soil bacteria belonging to the genera Rhizobium, Sinorhizobium, Azorhizobium, Mesorhizobium, Allorhizobium, and Bradyrhizobium and leguminous host plants is governed by signal exchanges between the two partners. The first signals, flavonoid molecules excreted by the plants, induce the expression of bacterial nodulation genes responsible for the synthesis of bacterial signal molecules, the Nod factors (Dénarié et al. 1996). These molecules elicit the formation of new organs, the root nodules, on the plants. Nodules are invaded by symbiotic bacteria, in which nif genes determine the enzyme nitrogenase capable of reducing atmospheric nitrogen to ammonia (Gibson et al. 2008). The fixed nitrogen source can be utilized by the host plant; therefore, 
legumes are able to tolerate nitrogen-deprived environments. The transition of free-living bacteria to the symbiotic state of bacteroids implies multiple metabolic and morphological changes, absolutely necessary for the bacteria to survive in a new environment and to perform new tasks (Jones et al. 2007).

Previously, the role of the TA locus ntrPR of Sinorhizobium meliloti, the microsymbiont of alfalfa, has been investigated (Bodogai et al. 2006). The $n t r P R$ operon represents a vapBCtype TA system, which is the most abundant group of the seven typical TA gene families, classified according to their modular genetic organization and sequence similarities (Gerdes et al. 2005, Jørgensen et al. 2009). The antitoxin NtrP carries a SpoVT/AbrB-like domain, and the toxin NtrR contains a PIN domain (Puskás et al. 2004). The general organization and the negative autoregulation of the module are highly similar to other known TA systems. This first example of TA loci in symbiotic bacteria has been shown to have an important influence on the plant-bacterium interaction. When the toxin gene $n t r R$ was inactivated by a Tn 5 insertion, the mutant strain developed a higher number of root nodules on alfalfa, especially in the presence of combined nitrogen. Moreover, these bacteria induced more efficient nitrogen-fixing nodules, since bacteroids expressed nif genes at an elevated level (Oláh et al. 2001).

Our aim was to examine whether vapBC-type TA modules may also exist in the symbiotic nitrogen-fixing bacterium $\mathrm{Bra}$ dyrhizobium japonicum, the microsymbiont of soybean (Glycine $\max (\mathrm{L}$.) Merr.). Soybean is an important crop used for human food and livestock feed throughout the world. Although $v a p B C$-type loci represent an abundant group of TA families, their presence and copy number vary considerably in different species. Escherichia coli, for example, does not contain vapBC-type modules; in contrast, Mycobacterium tuberculosis and Archeoglobus fulgidus carry an extremely high number of PIN domain-type modules (Pandey and Gerdes 2005). By using similarity search and neighborhood analysis, we identified a putative TA-like system in B. japonicum. To study the role of this module, a mutant strain was constructed by deleting the whole operon. The absence of the module resulted in remarkable changes of lipid composition of membranes and caused altered generation time and cell morphology, suggesting new functions for a TA system.

\section{RESULTS}

\section{Identification and characterization of the bsl2435/bll2434 operon, a putative TA locus in the genome of Bradyrhizobium japonicum USDA110.}

A sequence similarity search using the deduced protein sequence of the rhizobial toxin NtrR (Oláh et al. 2001) as a query and gene neighborhood analysis pointed out a candidate TA system in the $B$. japonicum USDA110 genome. The chromosomal operon bs12435/bll2434 (Fig. 1A), designated as a bat/bto operon (Bradyrhizobium antitoxin/Bradyrhizobium toxin), encodes a protein pair that forms a possible TA module. The bat/bto locus consists of an upstream-located 285-bp open reading frame (ORF), bat, that encodes a putative protein of 94 amino acids (Fig. 1B) and a downstream-located 426-bp ORF, bto, that encodes a putative protein of 141 amino acids (Fig. 1C). The translational start codon for bto overlaps with the last base of the translational stop codon of bat, which is a strong indication of translational coupling. The Bat protein represents the putative antitoxin component, and it carries a PhdYefMlike domain. The best-characterized member of this protein family is Phd of bacteriophage P1, the antidote partner of Doc (Lehnherr et al. 1993). Smith and Magnuson (2004) proposed that TA systems are composed of two evolutionarily independent modules joined by a transition region. The first module is a repressor represented by a DNA binding domain at the N-terminal part of the antitoxin. The second module is formed by the C-terminal part of the antitoxin and the toxin protein. Recombination in the transition region may contribute to TA diversity. Further sequence analysis revealed that the Bat protein may also be composed from two different modules. Interestingly, the $\mathrm{N}$-terminal part of the protein exhibited a higher degree of identity to the Phd module (Fig. 1B), whereas the Cterminal part showed similarity to the AbrB domain of the NtrP antitoxin, a member of the vapBC-type $n t r P R$ system of S. meliloti (Bodogai et al. 2006).

The Bto protein representing the putative toxin component contains a PIN domain (Fig. 1C) that has been identified in many bacteria, Archaea species, and eukaryota (Makarova et al. 1999). PIN domains comprise a large family of proteins characterized by the presence of four invariable acidic residues and a less conserved general amino-acid sequence identity (Arcus et al. 2004; Makarova et al. 1999). FitB, the toxin component of fitAB of Neisseria gonorrhoaea (Mattison et al. 2006), presents $39 \%$ identity to the Bto protein (Fig. 1C). It is worth noting that one of the conserved aspartic acid residues at the $\mathrm{C}$-terminal region is replaced by an asparagine in the Bto protein. According to these data, the structural organization of the bat/bto operon corresponds to that of the known bacterial TA modules.

\section{Activity of the bat/bto promoter.}

The negative autoregulation of TA operons by either TA complexes or free antitoxins is a common property of the characterized TA systems (Gerdes 2000; Gerdes et al. 2005; Oláh et al. 2001). To examine the regulation of the bat/bto operon, the plasmid pMP105, carrying the promoter region on a 379bp fragment upstream of a promoterless $l a c Z$ gene, was introduced into wild-type, bat/bto mutant, and complemented $B$. japonicum strains, and $\beta$-galactosidase activities were determined. The enzyme activity determined in the mutant strain was considerably lower $(5.2 \pm 0.5$ Miller units $)$ than that in the wildtype background (114.8 \pm 3.9 Miller units) (Fig. 2A, bars 2 and 1 , respectively) or in the complemented strain $(117.3 \pm 6.1$ Miller units) (Fig. 2A, bar 3), indicating that the regulation of the bat/bto operon does not exhibit the characteristics of typical TA modules.

Examination of the chromosomal neighborhood of the bat/bto operon revealed that it is located upstream of the $g l p D$ and downstream of the $g l p R$ genes (Fig 1A). The well-characterized $g l p D$ of $E$. coli encodes the enzyme glycerol-3-phosphate $(\mathrm{G} 3 \mathrm{P})$ dehydrogenase. The expression of $g l p D$ is negatively regulated by the repressor protein GlpR, which binds to multiple operator sequences in the $g l p D$ promoter (Yang and Larson 1996, 1998; Ye and Larson 1988). The presence of the inducer G3P reduces the binding activity of GlpR to the operators and thereby releases repression of the $g l p$ genes. The putative promoter region of the bat/bto operon in B. japonicum partially overlaps the putative promoter region of $g l p D$ (Fig. 2B), which is transcribed in the opposite direction from the complementary strand. Using the PromScan software, we could identify two putative GlpR binding regions in this intergenic sequence (Fig. 2B). Further examination revealed the presence of repeated sequences similar to the characteristic GlpR binding sites identified by computer-assisted analysis of Rhizobia (Danilova et al. 2003). The consensus sequence determined from data of three other Rhizobium species contains three to four direct repeats of -TTTCGTT- separated by 3 to 4 nucleotides (nt) (Danilova et al. 2003). The putative GlpR binding sites in Bradyrhizobium species contain two repeats without a space. One of them partially overlaps with a direct repeat sequence that, similarly to other TA modules (Bodogai et al. 
2006; Magnuson and Yarmolinsky 1998; Marianovsky et al. 2001), may represent a potential binding site for the TA complex. The other putative GlpR binding site is located just upstream of the $\operatorname{llpD}$ gene. We supposed that a potential competition of the TA complex and GlpR for the overlapping binding sites in the promoter region of bat/bto may influence the regulation of the bat/bto system of $B$. japonicum.

To examine this assumption, $\beta$-galactosidase activity expressed from plasmid pMP105 was determined in wild-type bacteria grown in minimal medium (MM) containing the inducer glycerol, the precursor of G3P. The activity was considerably higher than that obtained in MM without glycerol (Fig. 2A, bars 4 and 5) demonstrating that the expression of the TA module was positively influenced, probably by the inhibition of GlpR binding. Since bat/bto mutant cells were not able to grow in MM, we could not perform similar experiments with strain MP99. Wild-type bacteria grown in PSY medium (peptone, salt, and yeast extract) (Hahn and Hennecke 1984) with glycerol also exhibited a higher activity level than in PSY medium without glycerol (Fig. 2A, bars 6 and 1, respectively). In contrast to other TA systems, however, the very low expression levels observed in the deletion mutant MP99, as compared with those of the wild-type and complemented strains, indicated that the TA complex may influence its expression positively.

\section{The effect of ectopic expression of Bat and Bto proteins on the viability of Escherichia coli.}

To test the presumed toxic properties of the Bto protein, we examined the viability of $E$. coli strains carrying the bto gene and, as a control, either the bat gene or the bat/bto operon cloned in the vector pET-28. The gene expression was induced by adding isopropyl $\beta$-D-1-thiogalactopyranoside (IPTG) to the cells and, subsequently, the growth of the cultures and the number of viable cells was determined. Surprisingly, E. coli cells containing the bto toxin gene (plasmid pMP113) showed similar growth properties as the control cells carrying the vector plasmid (Fig. 3A), but the strains expressing the cloned antitoxin (pMP112) or the bat/bto operon (pMP114) grew very poorly (Fig. 3A). In accordance with the growth properties, the number of viable cells containing either the plasmid pET-28 or pMP113 continuously increased, whereas the living-cell number of the strains with plasmids pMP112 or pMP114 drastically decreased by the third hour after induction (Fig. 3B). These data revealed that the bat/bto system may be composed

A

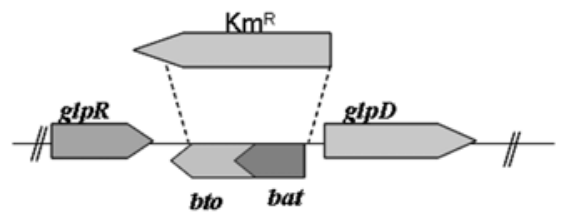

B Bat

MADHNTAPDTLPADDTWTLANAKARLSQVIDRAQTGPQI-ITRHGKPNAVIVSAEEWARK 59 Phd of $\varnothing$ P1 -----------MQSINERTARGNLSEVLNNVEAGEEVEITRRGREPAVIVSKATFE-- 45

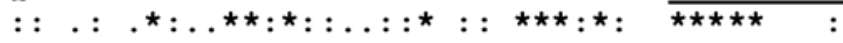

Bat TARKGTLAEFLLASPLRGADLALERMHDAPRDEMP- 94

Phd of $\varnothing$ P1 AYKKAALDAEFAS--------LFDTLDSTNKELVNR 73 $::^{\star} .:^{\star}:::$ : : : : : :

Bat

MADHNTAPDTLPADDTWTLANAKARLSQVIDRAQTGPQIITRHGKPNAVIVSAEEWARKT 60 NtrP MP--VPLPSSRPKEVKLFRNNRSQAVRIPAEFELPGDRVLIRR-EGTRLII--EPIARPA 55

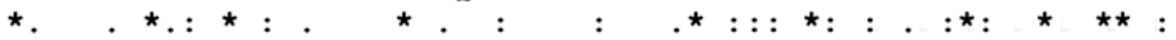

Bat

ARKGTLAEFLLASPLRGADLALERMHDAPRDEMP-- 94

NtrP DIVELLAEWKKEAPL-GPEDRF PDVEDIPARPEKIF 90 $\star \star \star: \quad: \star \star \star .:: \quad: . \star \star$

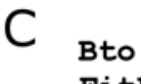

MNLLLDTNVLSEVQRPAPSPKVLAWLDTIDEDRAFISVASIAELRRGIALLEDGRRRSAL 60 -MILLD TNVI SEPLRPQPNERVVAWLDSLI LEDVYLSA ITVAELRLGVALLLNGKKKNVL 59

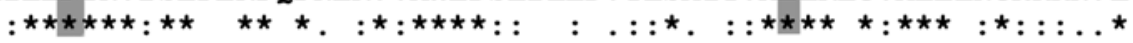

Bto
FitB AAWLAHDLPARFADRVLPIDHAVAEHWGDLMAQSRRSGVTLSVMDGFFAATALAHSLSLV 120 HERLEQSILPLFAGRILP FDEPVAAI YAQIRSYAKTHGKEIAAADGYIAATAKQHSLTVA 119

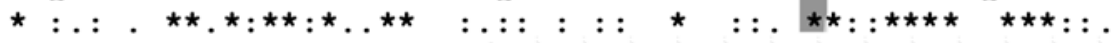

$\begin{array}{ll}\text { Bto } & \text { TRNVKDFAAFGVPLLNPWDDP } 141 \\ \text { FitB } & \text { TRDTGSFFAADVAVFNPWHD- } 139 \\ & \star \star . . . * \star . \star . .: * \star \star . \star\end{array}$

Fig. 1. A, Organization and chromosomal neighborhood of the bat/bto module. The bat/bto operon is located between the $g l p D$ and $g l p R$ genes and is transcribed from the complementary strand in the opposite direction. The orientation and insertion site of the kanamycin-resistance cassette replacing the bat/bto genes in MP99 deletion mutant is shown above the module. B, Alignment of the deduced amino-acid sequence of the Bat protein with antitoxins Phd of phage P1 and NtrP of Sinorhizobium meliloti. The N terminal parts of Phd and Bat show 23\% identity in 59 amino acids, but their C terminal parts are different (5.7\% identity in 35 amino acids). In contrast, Bat and NtrP exhibit homology at their C terminal parts (24\% identity in 34 amino acids), whereas the $\mathrm{N}$ terminal regions are different (16.7\% identity in 60 amino acids). A recombination junction proposed for Phd antitoxin (Smith and Magnuson 2004) is also present in Bat (underlined) and is located within the transition region. C, Alignment of the deduced amino-acid sequence of Bto toxin with FitB, the toxin component of the fitAB module of Neisseria gonorrhoaea (Mattison et al. 2006). The two sequences are 39\% identical. The conserved acidic residues are shaded. The aspartate residue near to the $\mathrm{C}$ terminal end in FitB is replaced by an asparagine in the Bto protein. 
of an active antitoxin and a functionally inactive toxin component. The more pronounced decrease of the number of viable cells in the presence of both components suggests a role for the toxin via complex formation with its antitoxin partner.

\section{The altered division rate of the bat/bto mutant strain is dependent on the nitrogen and carbon sources of the growth medium.}

Deletion of the bat/bto operon of B. japonicum resulted in a considerably decreased generation time of the mutant strain MP99 (2.5 h) compared with that of the wild-type bacteria (14 h) in yeast extract mannitol (YEM) medium (Fig. 4A). Growth stopped when the optical density at $600 \mathrm{~nm}\left(\mathrm{OD}_{600}\right)$ of the MP99 culture reached 0.8 . Under these conditions, more than $80 \%$ of the cells sustained their viability for more than 6 days. The growth of bacteria could be restored by transferring the cells into fresh medium, in which higher optical densities $\left(\mathrm{OD}_{600}=1.2\right)$ were obtained (data not shown). In PSY medium, the generation time of MP99 was even shorter (about 2 h) and the culture could reach a much higher OD (Fig. 4B). To determine which component of the PSY medium was responsible for the improved generation time, the effect of two components, peptone and biotin, was tested by adding them separately to YEM medium. The presence of biotin did not improve bacterial growth in YEM. Moreover, biotin was also not required for the growth of wild-type B. japonicum strains in PSY medium (data not shown). The addition of peptone, a rich source of complex nitrogen and carbon, however, promoted a better growth of MP99 in YEM medium (data not shown), suggesting a role of the complex nitrogen source in the fast growth. This was confirmed when MM containing ammonium sulphate as nitrogen source was used. The bat/bto mutant was unable to grow in MM, whereas the growth of the wild-type bacteria was only delayed (Fig. 4C). When peptone was added to MM, the growth of MP99 was similar to that in YEM (Fig. 4D).

To examine whether the altered division rate of the mutant strain was due to the deletion of the bat/bto module, MP99 was complemented in trans with a plasmid containing the bat/
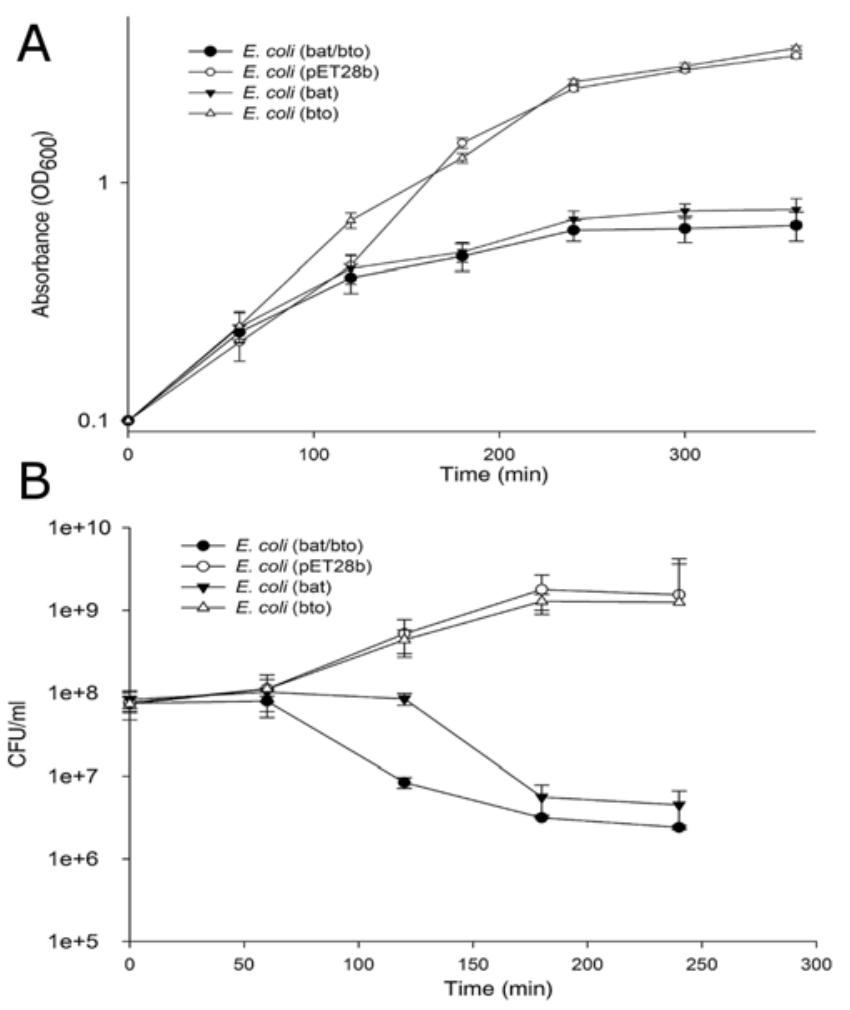

Fig. 3. A, Growth and B, viability of Escherichia coli carrying the vector plasmid (pET-28b, open circles), the cloned bat antitoxin (pMP112, filled triangles), the bto toxin (pMP113, open triangles), or both genes (pMP114, filled circles) expressed from the isopropyl $\beta$-D-1-thiogalactopyranoside (IPTG)-inducible promoter of plasmid pET-28b. E. coli cells grown in Luria Bertani (LB) medium were induced by $1 \mathrm{mM}$ IPTG at an optical density at $600 \mathrm{~nm}\left(\mathrm{OD}_{600}\right)=0.1$. Growth of bacteria was followed by measuring $\mathrm{OD}_{600}$. Samples were taken at the indicated time and were diluted and plated on LB medium to determine the number of viable cells. Standard deviations were calculated from the results of three experiments.

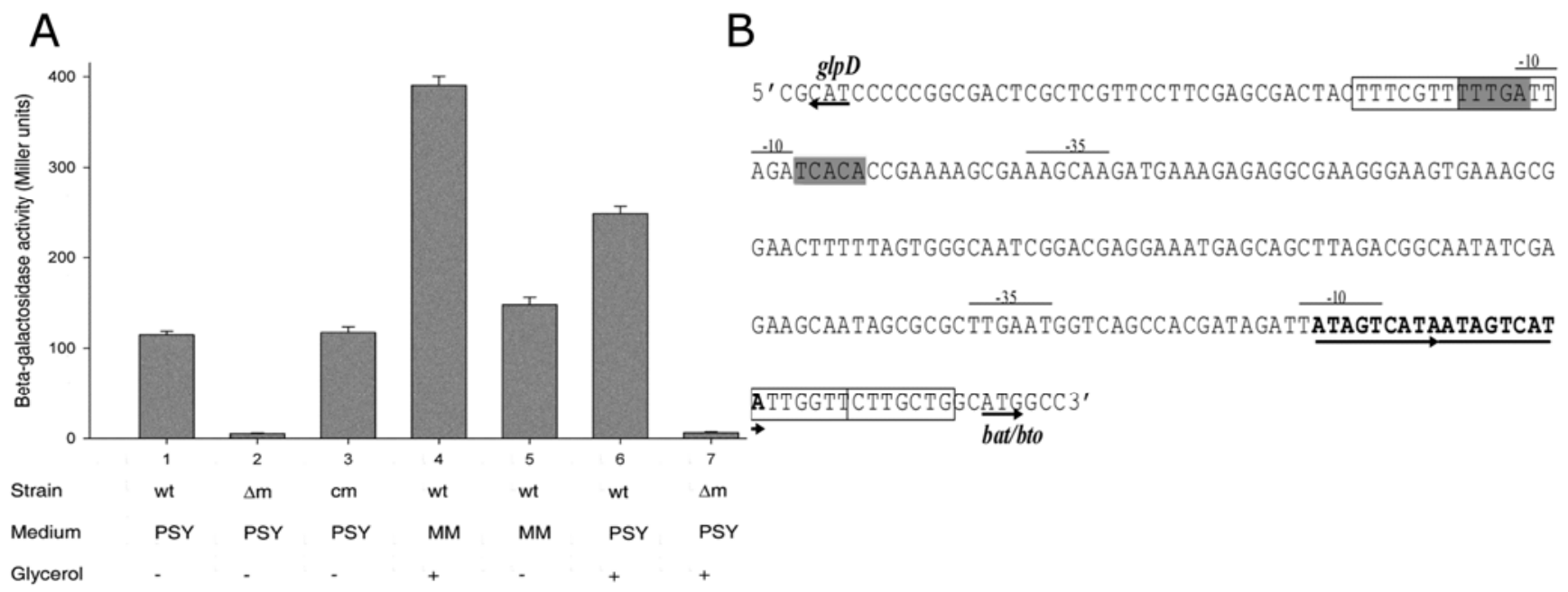

Fig. 2. A, Activity of the bat/bto promoter. $\beta$-galactosidase activity expressed from plasmid pMP105 carrying a 379-bp fragment consisting of the 233-bp intergenic region, 144 and 2 bp of the glpD and bat/bto coding regions, respectively. Enzyme activities of Bradyrhizobium japonicum wild-type (1, 4, 5, 6), MP99 deletion mutant $(2,7)$, and MP120 complemented (3) strains carrying pMP105 were determined. Bacteria were grown in peptone, salt, and yeast extract (PSY; $1,2,3,6,7)$ or in minimal medium $(\mathrm{MM} ; 4,5)$ at $31^{\circ} \mathrm{C}$, to an optical density at $600 \mathrm{~nm}=0.5$. Cultures were induced by the addition of $0.04 \%$ glycerol as indicated. The measurements were repeated five times. Wt $=$ wild-type strain, $\Delta \mathrm{m}=$ deletion mutant MP99, and $\mathrm{cm}=\mathrm{complemented}$ strain MP120. B, The intergenic region of $g l p D$ and the bat/bto module with repeated sequences (ATAGTCAT) representing potential binding sites of the Bat/Bto complex (underlined with arrows). Potential -10 and -35 regions in the promoter of $g l p D$ and bat/bto are superlined. A TGN extension of the -10 motif in

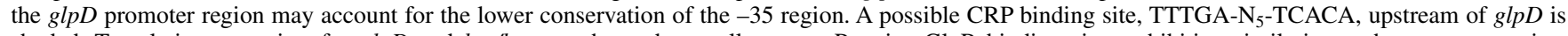
shaded. Translation start sites for $g l p D$ and bat/bto are shown by small arrows. Putative GlpR binding sites exhibiting similarity to the sequence unit TTTCGTT- characteristic for $\alpha$-proteobacteria (Danilova et al. 2003) are boxed. 

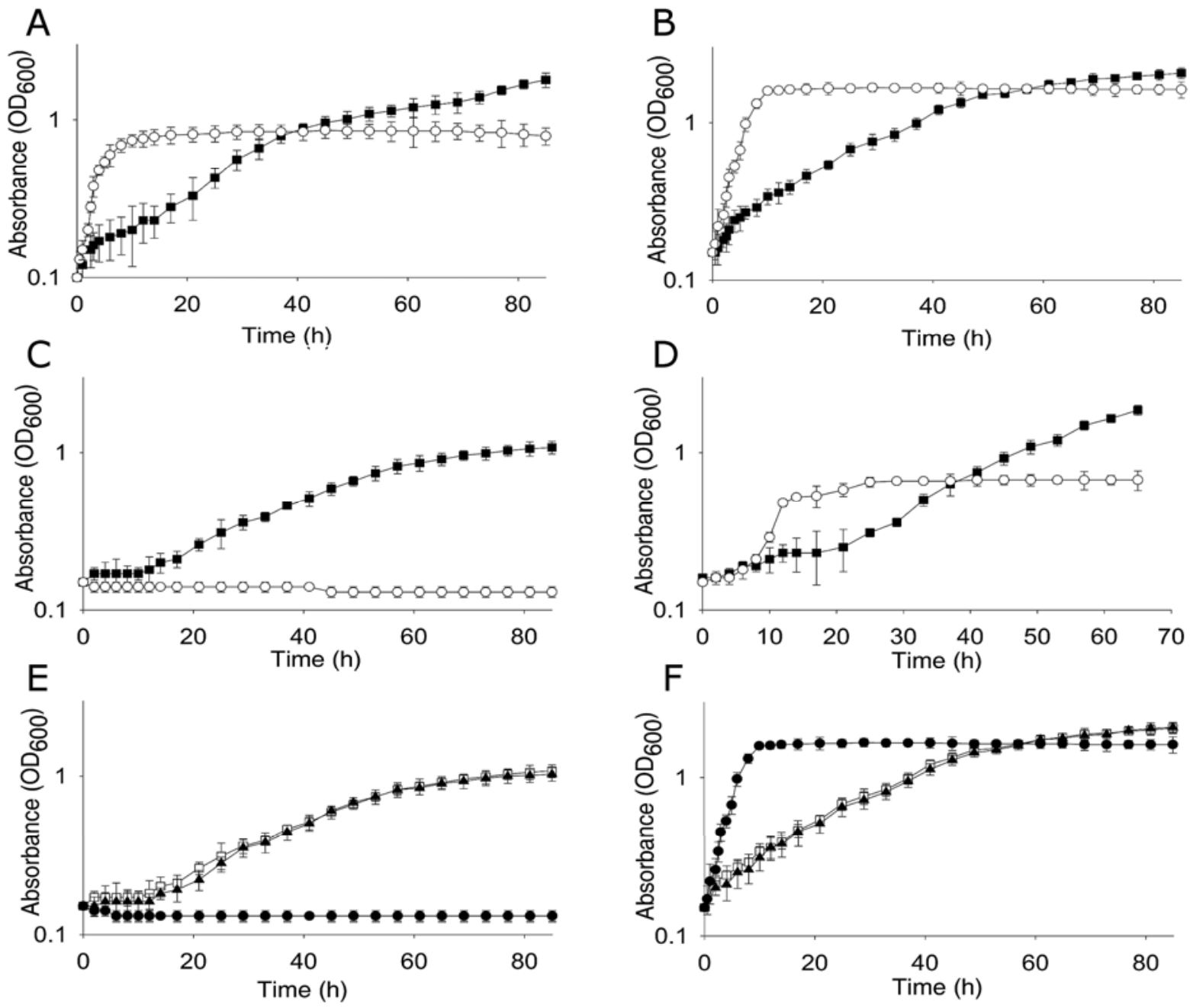

Fig. 4. A, B, C, and D, Growth curves of Bradyrhizobium japonicum wild-type (filled squares) and bat/bto mutant MP99 (open circles) strains in A, yeast extract mannitol (YEM), B, peptone, salt, and yeast extract and $\mathbf{C}$, minimal medium (MM) without and $\mathbf{D}$, with the addition of peptone. $\mathbf{E}$ and $\mathbf{F}$, Comparison of the growth of B. japonicum wild type, deletion mutant MP99, and MP120 complemented strains in MM (E) and YEM (F) media. B. japonicum wildtype strain with plasmid pRK290, open squares; mutant MP99 strain with pRK290, filled circles; and complemented strain with the recombinant plasmid pMP117, filled triangles. Cultures were grown at $31^{\circ} \mathrm{C}$ in liquid medium containing the appropriate antibiotics. At the beginning of the experiments, starter cultures were diluted in the corresponding media to obtain an optical density of 0.15 . The growth of bacteria was followed by measuring the optical density at $600 \mathrm{~nm}$. Standard deviations were calculated from the data of four experiments.

bto coding region and the putative promoter. Whereas the presence of the vector plasmid pRK290 had no influence on the growth properties of either the wild-type strain or the mutant MP99 (Fig. 4E and F), the growth of the complemented strain MP120 was similar to that of the wild-type strain, both in MM and YEM media (Fig. 4E and F, respectively), suggesting that the altered generation rate of the MP99 mutant strain was due to the absence of the bat/bto operon. The revertant MP119 strain (obtained by restoring the bat/bto operon in the mutant MP99 strain) exhibited a similar growth pattern as wild-type and MP120 complemented strains (data not shown).

\section{Cell size and mechanical parameters are affected by the bat/bto mutation.}

The faster-dividing MP99 cells also exhibited considerably altered morphological properties (Fig. 5A). Three-dimensional surface profiles of living cells obtained by atomic force microscopy (AFM) demonstrated that wild-type bacteria had elongated cylindrical shape ( 2 to $2.5 \mu \mathrm{m}$ long and 0.5 to $0.6 \mu \mathrm{m}$ wide), whereas the mutant cells were more compact and round shaped with decreased length (1 to $1.5 \mu \mathrm{m}$ ) and increased width (1 to $1.4 \mu \mathrm{m}$ ). The height profile shown in Figure 5B was determined between the markers indicated in Figure 5A. The three- dimensional surface profile of complemented strain MP120 showed similar elongated cylindrical cells with the same dimensions as was observed for the wild-type cells (data not shown), demonstrating that the wild-type morphology was restored by introducing the bat/bto genes.

Since the cell sizes of the wild-type and the mutant bacteria were remarkably different, we compared the number of colonyforming units of the two strains (grown in PSY medium) at increasing $\mathrm{OD}_{600}$ values. The cell numbers of the wild-type strain were lower between $\mathrm{OD}_{600}=0.3$ to 0.5 , but the difference was not statistically significant (data not shown). At higher OD values, the cell numbers were nearly identical.

To investigate the mechanical properties of the mutant cells, local force measurements were performed by recording the indentation of the AFM cantilever in function of the vertical displacement of the $\mathrm{z}$ piezo. As the distance and indentation curves demonstrated, greater distance (Fig. 6A) and indentation (Fig. 6B) values were obtained with the mutant cells compared with those obtained with the wild-type strain, indicating a softer cell surface (Bálint et al. 2007). This was confirmed by the calculated elastic modulus, which was about one order of magnitude lower for the mutant strain. $\mathrm{E}_{\mathrm{m}}=0.6 \pm 0.24 \mathrm{MPa}$ and $\mathrm{E}_{\mathrm{m}}=4.5 \pm 0.92 \mathrm{MPa}$ for the mutant and the wild-type 

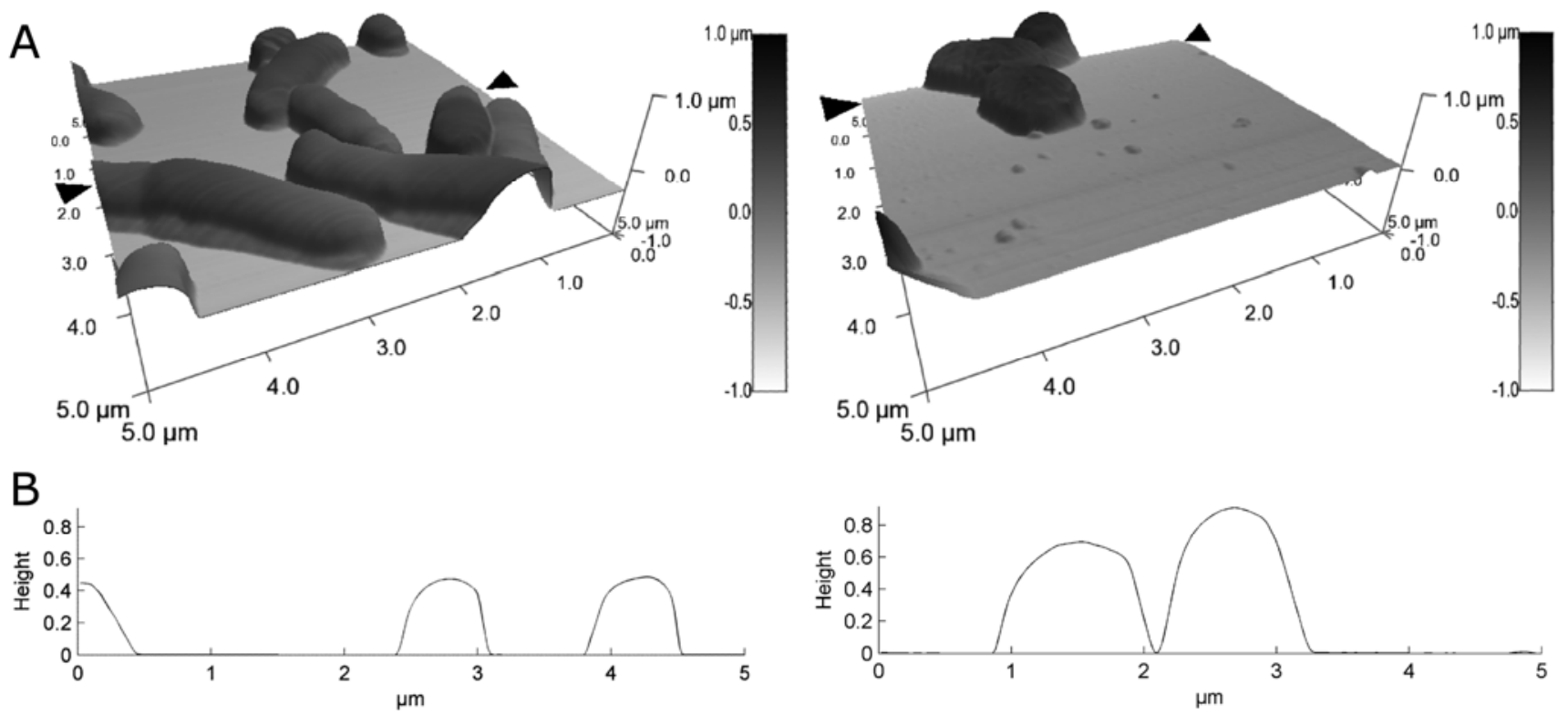

Fig. 5. A, Three-dimensional atomic force microscopy (AFM) profiles of Bradyrhizobium japonicum wild-type (left) and bat/bto mutant MP99 (right) cells constructed from $5 \times 5-\mu \mathrm{m}$ scan images. Both trace and retrace images were measured at a scan rate of 0.3 to 1.0 lines s ${ }^{-1}$. B, Height profiles of AFM images were drawn between the markers (black triangels). Images were made after immobilization of bacterial suspensions grown at $31^{\circ} \mathrm{C}$ in yeast extract mannitol medium on a poly-L-lysine precoated mica surface.
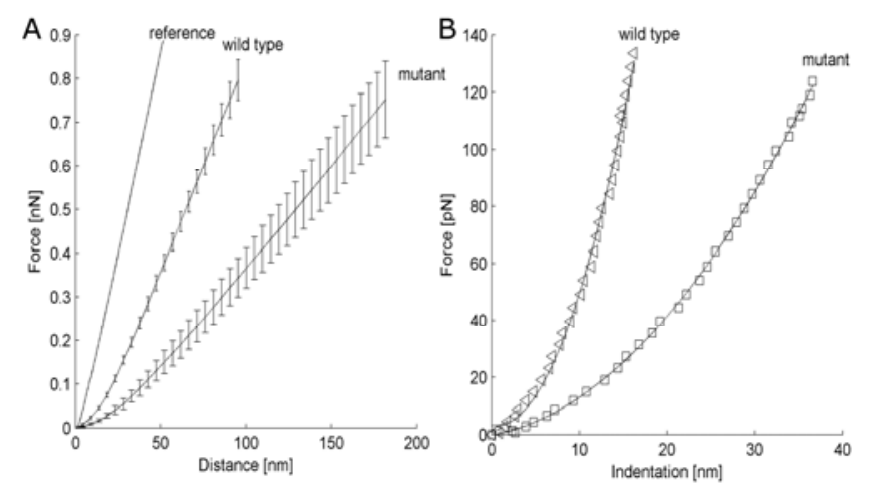

Fig. 6. Elastic properties of Bradyrhozobium japonicum wild-type and bat/bto mutant bacteria measured by atomic force microscopy. A, Forcedistance curves with standard deviation error bars. B, Force-indentation curves calculated by subtracting the reference from the curves of wild-type and mutant cells. Lines are the fitted second order polynomials. Bacterial suspensions were immobilized after being grown at $31^{\circ} \mathrm{C}$ in yeast extract mannitol medium on a poly-L-lysine precoated mica surface.

cells, respectively. To explain the observed morphological changes, the amount and composition of several cell-membrane components of the mutant and wild-type strains were investigated in further experiments.

\section{The bat/bto mutation results in differences in the pattern of lipopolysaccharides (LPS) and phospholipids (PL).}

LPS contributing to the structural and physiological integrity of the bacterial cell were analyzed in further experiments. Rhizobial LPS also play an important role in the symbiotic infection process. Rhizobium mutants producing defective LPS that lack the $O$-chain polysaccharide were shown to be defective in nodulation (Stacey 1991). The differences in LPS pattern between the wild-type and MP99 strains were remarkable (Fig. 7). The heterogeneous banding region of wild-type LPS (Fig. 7, lane 1) consisted of LPS molecules that were separated according to the number of $O$-antigen repeating units or differences in the electric charges of these units (Carrion et al. 1990). The low molecular weight bands (Fig. 7, lanes 2 and 4)

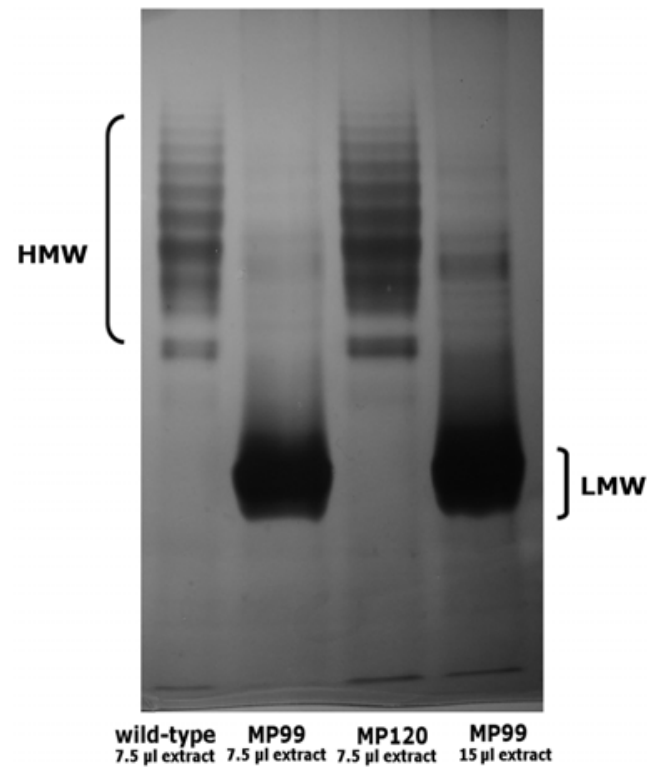

Fig. 7. Sodium deoxycholate-polyacrylamide gel electrophoresis (DOCPAGE) of polysaccharide extracts from Bradyrhizobium japonicum wildtype, mutant MP99, and complemented MP120 strains silver-stained for lipopolysaccharides (LPS). Two types of LPS of differing molecular weight are indicated (HMW and LMW). Polysaccharides were extracted from cultures grown in peptone, salt, and yeast extract medium at $31^{\circ} \mathrm{C}$ to an optical density at $600 \mathrm{~nm}=0.6$. DOC-PAGE was performed on $18 \%$ polyacrylamide gels.

represented incomplete LPS of the mutant strain, which either lacked the entire $O$-antigen repeating unit or contained only one to two repeating units. The mutant also produced lower amounts of complete LPS molecules with altered mobility as compared with the wild-type strain (Fig. 7, lane 4). In the complemented strain MP120 that carried the reintroduced bat/bto operon, the heterogenous banding region characteristic for the wild-type LPS pattern was restored (Fig. 7, lane 3).

The considerable change in the shape of the cells and the softness of the mutant membrane observed by AFM force measurements suggested an alteration of the membrane com- 
position of the bat/bto mutant. To determine the PL composition of membranes of wild-type and MP99 strains, thin-layer chromatography coupled with gas chromatographic-mass spectrometry (GC-MS) determination of fatty acids was used (Fig. $8)$. The main PL of the wild-type cells were phosphatidylethanolamine (PE), phosphatidylcholine (PC), cardiolipin (CL), phosphatidylglycerol (PG), the intermediate lipid mono-methylphospatidylethanolamine (MMPE), and lysophosphatidylethanolamine. There were striking differences in the PL composition of the two strains (Fig. 8A and B), of which the most remarkable was the complete lack of PC in the mutant. The main PL in both cell types was PE, which increased in parallel with the disappearance of PC. CL was present in higher amounts in the mutant, at the expense of its precursor, PG.

As the physico-chemical properties of PL are determined by both the head group and the alkyl chain regions, the fattyacid composition of total PL was also investigated from both wild-type and MP99 strains (Fig. 8C and D). In the wild-type bacteria, cis-vaccenic acid (18:1) was the major fatty acid, making up about $80 \%$ of total fatty acids, the amount of which decreased to less than one third $(25 \%)$ in the mutant strain. As the amount of palmitoleic acid (16:1) increased more than 50 times $(0.4 \%$ in the wild-type vs. $25.2 \%$ in the mutant cells), it was obvious that fatty-acid elongation was blocked in the mutant strain. However, there was a more overall modification in fatty-acid synthesis as palmitic acid (16:0) content increased from $14 \%$ in the wild type to $42 \%$ in the mutant cells, resulting in a considerable decrease in the ratio of unsaturated fatty acids in the mutant $(50.9 \%)$ compared with a much higher value in wild-type cells $(83.3 \%)$, suggesting a fundamental alteration in the lipid chain order and the polymorphic characteristics of membrane lipids.

To explain the profound changes observed in PL composition, the expression of several genes involved in PC biosynthesis was investigated.

\section{In the bat/bto mutant cells, transcripts for the two PL $N$-methyltransferases PmtA and PmtX1 are not detectable.}

Biosynthesis of PC from PE is accomplished by three successive methylation steps in many prokaryotes. An alternative direct pathway that requires the presence of free choline and of

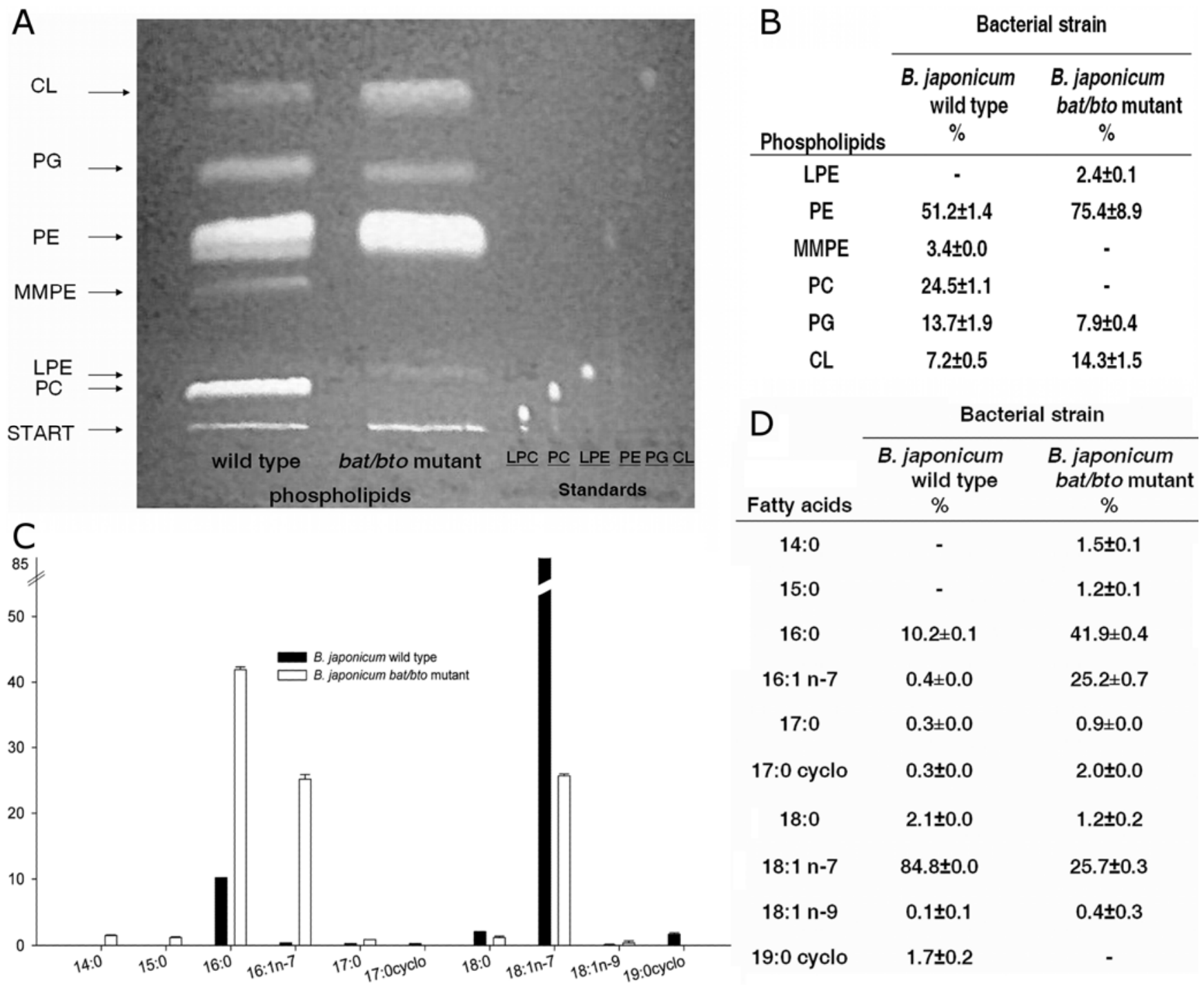

Fig. 8. Lipid analysis of Bradyrhizobium japonicum wild-type and MP99 mutant cells. A, Thin-layer chromatography of phospholipid samples performed on silica gel G plates. Samples were visualized by spraying with $0.05 \%$-anilinonaphtalene-1-sulfonate. B, Phospholipid composition was determined after transmethylation. The identified phospholipids are: LPE $=$ lysophosphatidylethanolamine, PE $=$ phosphatidylethanolamine, PG $=$ phosphatidylglycerol, $\mathbf{C L}=$ cardiolipin, $\mathrm{PC}=$ phosphatidylcholine, and MMPE = mono-methyl-phosphatidylethanolamine. $\mathbf{C}$ and $\mathbf{D}$, Fatty-acid composition of total lipid extracts. The amount of fatty acids as the percentage of total lipids is indicated with standard deviation values. All experiments were done in triplicate. 
PC synthase was documented in several bacteria (MartínezMorales et al. 2003). The absence of PC from the membranes of MP99 mutant cells was an intriguing observation. Moreover, MMPE, the first intermediate during the conversion of PE to PC was also absent from the mutant membranes. In B. japonicum, the first methylation step is performed predominantly by the enzyme PmtA, whereas PmtX1 catalyzes mainly the second and third subsequent methylation steps (Hacker et al. 2008). With the use of reverse transcription-polymerase chain reaction (RT-PCR), we checked the level of mRNA from these two genes. We observed that both the pmtA and pmtXl transcripts were detectable in the wild-type cells (Fig. 9, lanes 5 and 8), but they were not detected in the mutant strain (Fig. 9, lanes 6 and 9) or in the mutant strain carrying the vector plasmid pRK290 (data not shown). In the complemented MP120 strain, pmtA and $p m t X 1$ mRNA levels were restored (Fig. 9, lanes 7 and 10). Therefore, the lack of the enzymes catalyzing the methylation reactions explained the absence of PC in the bat/bto mutant bacteria. As a positive control, the expression of histidyl-tRNA synthetase was detected in all strains (Fig. 9, lanes 2, 3, and 4).

\section{Symbiotic phenotype of the bat/bto mutant.}

We have shown previously that a mutation in the toxin component of the $n t r P R$ module of $S$. meliloti results in increased nodulation and more efficient nitrogen-fixation capacity in symbiosis with the host plant alfalfa (Oláh et al. 2001). Since both toxins Bto and NtrR are PIN domain homologs, we examined whether the Bto toxin may have a similar effect on symbiotic properties. Soybean plants were inoculated with mutant MP99 and the wild-type strain, and nodule formation and plant biomass production were determined after 60 days. Deletion of the bat/bto region resulted in decreased symbiotic capacity. The mutant strain produced about $60 \%$ fewer nodules on soybean $(51.7 \pm 6$ nodules per plant formed by the wildtype bacteria compared with $22.5 \pm 4$ nodules per plant elicited by the mutant MP99 strain). The average dry weight of plants inoculated by the mutant strain was about $40 \%$ lower than that of the wild type-inoculated plants $(0.57 \pm 0.13$ and $0.95 \pm 0.12$ g per plant, respectively). The average dry weight of uninoculated plants was $0.38 \pm 0.07 \mathrm{~g}$ per plant.

Bacteria were recovered from 40 randomly collected nodules of both types, and 200 colonies from each inoculation were tested for kanamycin and spectinomycin resistance, the markers of the mutant and wild-type strains, respectively. All of the colonies (100\%) obtained from the MP99 mutant-elicited nodules were kanamycin resistant and exhibited the morphology of the MP99 mutant colonies (low levels of polysaccharide production). Their growth on YEM agar plates was also similar to that of the MP99 strain. Randomly selected colonies were further tested in YEM liquid medium, and their generation times were identical to that of the mutant strain (data not shown). The nodules elicited by the wild-type strain contained only kanamycin-sensitive bacteria.

\section{DISCUSSION}

In this paper, we report the identification and experimental characterization of the first TA-like module of the soybean microsymbiont Bradyrhizobium japonicum. We demonstrate that the deletion of the TA module caused remarkable physiological alterations resulting in morphological and structural changes. The observed effects define new functions for a TA system.

TA loci have been grouped into seven families based on their module organization and domain structure (Gerdes et al. 2005; Jørgensen et al. 2009). Members of the vapBC family are composed of a toxin carrying a PIN domain and an anti- toxin containing one of the DNA-binding motifs AbrB, cHTH, $\mathrm{Phd} /$ YefM, or MetJ/CopG. The chromosomally located bat/bto system is composed of a Phd/AbrB-type antitoxin and a PIN domain-type toxin.

Although the size and organization of the genes and the deduced amino-acid sequences of the proteins encoded by the bat/bto module classified it as a TA system belonging to the $v a p B C$-family, the expression of the module did not exhibit the typical negative autoregulatory properties of most TA modules. The expression level was higher in the wild-type background than in the mutant strain, suggesting a positive role for the TA complex. Since the putative binding site for the Bat/Bto complex follows the -10 region, a direct autoactivation seems unlikely. Further experiments are required to clarify this mechanism. Two modules with similar properties were identified in Mycobacterium tuberculosis, where RelB and RelF antitoxins acted as transcriptional activators on their respective promoters (Korch et al. 2009). However, together with their toxin pairs, these proteins repressed the expression to basal levels. The absence of a typical autorepression was also demonstrated in Staphylococcus aureus. The promoter of the mazEF module in this bacterium was downregulated by $\operatorname{sig} B$ encoding an alternative sigma factor and was activated by a SarA transcriptional regulator (Donegan and Cheung 2009). In addition to the lack of negative autoregulation of bat/bto, the partial overlapping of the potential binding sites of GlpR protein and the Bat/Bto complex suggested the involvement of the downstream-located GlpR protein in bat/bto regulation. Indeed, in the presence of the inducer glycerol, an increased promoter activity was observed in the wild-type cells grown either in rich medium or MM.

In the genome of three Bradyrhizobium strains (B. japonicum USDA 110 and Bradyrhizobium sp. strains BTAi1 and ORS278) one of the multiple $g l p D$ copies is located downstream of $g l p R$. Putative GlpR binding sites could be localized only in the promoter region of these copies. However, none of these sequences contain three to four direct repeats of the consensus -TTTCGTT- separated by 3 to $4 \mathrm{nt}$, as was described for three other Rhizobium species (Danilova et al. 2003). The Bradyrhizobium promoters are characterized by the presence of T-rich sequences interrupted by 2 to $3 \mathrm{G} / \mathrm{C} \mathrm{nt}$.

Our observation that the ectopic expression of Bto toxin had no influence on the viability of $E$. coli suggested that the Bto protein has lost its function characteristic for the toxin components of TA modules. It is conceivable that the loss of toxicity is due to the replacement of one of the essential acidic residues with an asparagine near to the $\mathrm{C}$-terminal end. The structural analysis of PIN-domain proteins revealed that the quartet of acidic amino acids constitute the active site, which binds $\mathrm{Mg}^{2+}$ or $\mathrm{Mn}^{2+}$ ions and facilitates the cleavage of single-stranded

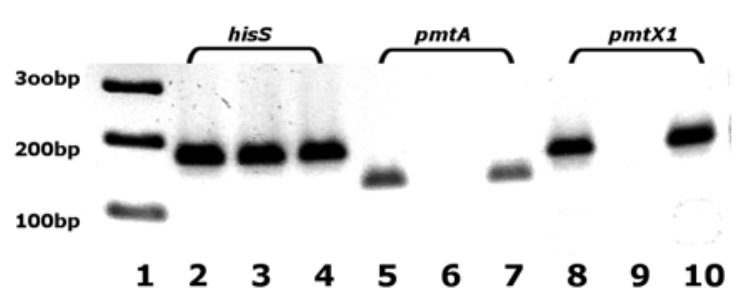

Fig. 9. Transcript levels of $p m t A$, pmtX1, and hisS genes. RNA was isolated from cultures of Bradyrhizobium japonicum strains grown in peptone, salt, and yeast extract medium at $31^{\circ} \mathrm{C}$. Reverse transcription was performed from identical amounts of RNA obtained from B. japonicum wild-type (lanes 2, 5, and 8), MP99 bat/bto mutant (lanes 3, 6, and 9), and MP120 complemented (lanes 4, 7, and 10) strains. Amplification reactions were done using gene-specific primers for hisS (lanes 2, 3, and 4), pmtA (lanes 5, 6 and 7), and pmtX1 (lanes 8, 9, and 10). Lane 1, DNA ladder. 
RNA (Bunker et al 2008). More surprisingly, the ectopic expression of either the Bat antitoxin or the complete module resulted in a remarkable loss of cell viability. Whether these unconventional properties of the bat/bto system are due to the binding of antitoxin to some yet unknown regulatory regions or to possible interactions with TA modules of $E$. coli remain to be further examined.

By analyzing nearly 400 natural isolates of $E$. coli, Mine and coworkers (2009) proved that $29 \%$ of the $c c d_{\mathrm{O} 157}$ variants were composed of an active antitoxin and an inactive toxin. Moreover, the $\mathrm{CcdB}$ toxin proteins were more diversified and lost their function more frequently than the antitoxins. Comparing the intergenic regions between $g l p D$ and $g l p R$ genes of three Bradyrhizobium species (B. japonicum USDA110 and Bradyrhizobium sp. strains BTAi1 and ORS278), we observed a considerable DNA sequence similarity, similar length, and the presence of identical putative binding sites for GlpR. We suppose that the bat/bto operon was acquired by horizontal gene transfer and was inserted between the $g l p D$ and the $g l p R$ genes of $B$. japonicum USDA110. The possible lack of stronger selective pressure may have resulted in the inactivation of toxin protein, whereas the antitoxin (and its complex with the cognate toxin) became part of a metabolic process such as the competition with the GlpR protein.

Deletion of the bat/bto operon resulted in alterations in several metabolic pathways leading to characteristic phenotypic changes. The electrophoretic pattern of LPS of cell membranes revealed the accumulation of incomplete LPS molecules. Comparison of the composition of PL and fatty acids in the wildtype and mutant strains showed substantial alterations. PC was completely absent in the mutant strain, whereas PE together with CL increased dramatically. It is known that PE and CL are both non-bilayer forming lipids. In the cells, the balance between bilayer and nonbilayer lipids is tightly regulated and has been shown to be essential for viability (Rietveld et al. 1993). The regulation of the tendency to form the hexagonal phase can be achieved by alterations in membrane fatty-acid composition that influence PL shape (Horváth et al. 1986). The cone-shaped geometry of PE with relatively small head group size coupled with the relatively large area occupied by the unsaturated 18:1 acyl chains promotes the formation of nonbilayer, hexagonal structures. This might explain why the content of unsaturated fatty-acid species (18:1) decreased in the mutant strain, which had a dramatically increased PE content. Taken together, it is highly conceivable that the above restructuring of lipids is aimed at reestablishing lateral packing order, bilayer stability, membrane permeability, and ultimately, membrane functionality in the mutant strain (Vigh et al. 2005).

In prokaryotes, one of the biosynthetic pathways to yield PC is the enzymatic methylation of PE catalyzed by PL $N$-methyltransferase (Pmt) in three consecutive steps using $S$-adenosylmethionine as methyl donor. Alternatively, PC can be synthesized directly from free choline by PC synthase (Pcs). Pcs is also present and functional in $B$. japonicum, although no uptake system exists for choline in this species (Boncompagni et al. 1999; Hacker et al. 2008). The block of the methylation pathway results in the complete absence of PC in the MP99 mutant strain. We have shown that the methylation steps are defective, since the transcripts of the genes coding for PmtA and PmtX1 (Hacker et al. 2008) were not detected in the mutant cells. We suppose that the absence of Bat/Bto indirectly affects these transcript levels either via the activation of a degrading factor or by influencing an unknown positive regulatory factor involved in the transcription of these genes.

The profound alterations in the lipid composition of the mutant membranes may result in changes in the cell division rate, cell shape, and membrane rigidity. Distribution of PL in membranes is an important factor in the process of divisionsite selection. At the midcell domain, optimal lipid composition is required for the Z-ring positioning. In E. coli, CLenriched domains were detected at the cell poles and at the division septum, suggesting their involvement in cell division (Kates 1986; Mileykovskaya and Dowhan 2005). Membrane synthesis is also required for cell expansion and might be regulated spatially and temporally in the same manner as cell-wall synthesis. The increased amounts of CL and PE and the incomplete LPS molecules in the mutant strain may, therefore, influence cell-division rate and cell shape by altering the formation of division-site selection and the elongation phase between two divisions. We assume that the incomplete LPS and the altered membrane composition may also be responsible for the lower symbiotic efficiency of MP99 strain. Previous data proved that exopolysaccharide and LPS molecules acting as signals to avoid plant defense reactions may have an important role in plant-bacterium interactions (Stacey et al. 1991).

G3P dehydrogenase encoded by the $g \operatorname{lpD}$ gene has a central function at the crossroad of the glycolytic pathway and the PL biosynthesis pathway. GlpD converts G3P, the key factor in the PL biosynthesis, to di-hydroxi-acetone-phosphate, an intermediate of pyruvate in the glycolytic pathway. Our data suggest that, in B. japonicum, the addition of glycerol resulted in a higher expression of the bat/bto genes, probably due to the absence of competing GlpR at the overlapping binding site. Further experiments are required to clarify whether the Bat/Bto proteins may also influence directly or indirectly the regulation of $g l p D$.

Chromosomally located TA systems of E. coli were shown to act as bacterial metabolic stress managers (Buts et al. 2005; Gerdes et al. 2005), associated with the modulation of the global level of translation under various stress conditions and nutrient limitation. In contrast to these data, deletion of the B. japonicum bat/bto operon resulted in alterations of several metabolic pathways and defective symbiotic performance, probably due to the changes in LPS and PL composition of the cellular membrane. In conclusion, the bat/bto operon seems to be involved in the maintenance of the normal physiological state of the cell, modulating the metabolic rates to a level that may support a better adaptation to environmental conditions.

\section{MATERIALS AND METHODS}

\section{Bacterial strains and growth conditions.}

Escherichia coli DH5 $\alpha$ (Maniatis et al. 1982) and its derivatives were grown at $37^{\circ} \mathrm{C}$ in Luria-Bertani (LB) medium (Maniatis et al. 1982) that was supplemented when appropriate with ampicillin $(100 \mu \mathrm{g} / \mathrm{ml})$, kanamycin $(\mathrm{Km})(50 \mu \mathrm{g} / \mathrm{ml})$, or tetracycline (Tc) $(10 \mu \mathrm{g} / \mathrm{ml})$. Bradyrhizobium japonicum USDA110 (wild type, spectinomycin-resistant) (Regensburger and Hennecke 1983) was cultivated at $31^{\circ} \mathrm{C}$ in YEM (yeastextract-mannitol) (Vincent 1970), PSY (Hahn and Hennecke 1984), or MM (Guerinot et al. 1990) containing the appropriate antibiotics: Sp, $50 \mu \mathrm{g} / \mathrm{ml}$; Km, $100 \mu \mathrm{g} / \mathrm{ml}$; chloramphenicol, $30 \mu \mathrm{g} / \mathrm{ml}$; Tc, $50 \mu \mathrm{g} / \mathrm{ml}$; or gentamicin, $150 \mu \mathrm{g} / \mathrm{ml}$. When required, a modified MM was used, in which mannitol was replaced by $0.4 \%$ (final concentration) of glycerol as the only carbon source present in the medium.

For the determination of generation times, B. japonicum wild-type USDA110, MP99, MP119, and MP120 strains were precultured in YEM medium, were washed with $0.9 \% \mathrm{NaCl}$ solution, and then, were diluted to an $\mathrm{OD}_{600}$ of 0.1 in the tested growth media YEM, PSY, and MM. The cultures were grown in flasks in a gyrotory water bath with $200 \mathrm{rpm}$ at $30^{\circ} \mathrm{C}$. Samples were taken at the indicated time points, and bacterial 
growth was followed by measuring the $\mathrm{OD}_{600}$. When required, peptone was added at a final concentration of $0.1 \%$. The experiments were repeated at least six times.

\section{DNA manipulations.}

Preparation of plasmid DNA, digestion with restriction enzymes, agarose gel electrophoresis, fragment isolation, cloning procedures, and transformation of $E$. coli cells were performed according to Maniatis and associates (1982). In PCR, Pfu polymerase (Fermentas, Vilnius, Lithuania) was used to obtain error-free products.

\section{Construction of strains and plasmids.}

Construction of a bat/bto deletion derivative of $\mathrm{B}$. japonicum. For the deletion of the bat/bto operon, PCR primers were designed to amplify a $1-\mathrm{kb}$ upstream region and a $1.2-\mathrm{kb}$ downstream region of the operon. The $5^{\prime}$ ends of two primers contain a BamHI restriction site each (shown in bold). The sequences of the primers are as follows: BAT1, 5'-CGTGGTCG TAGAGCTTCTTGA-3' and BAT2, 5'-GGATCCTGCCAGCA AGAACCAATA-3' for the amplification of the upstream region; BAT3, 5'-GGATCCCCCTATCTCAACCGCAC-3' and BAT4, 5'-GCATCACGGACCGTTTCAA-3' for the amplification of the downstream region. The PCR products were cloned separately in a pBluescript II $(\mathrm{SK}+)$ (Alting-Mees and Short 1989) derivative (BamHI site excised from multicloning site) to obtain plasmids pMP73 with the upstream region and pMP74 with the downstream region of the bat/bto operon. A SmaI-BamHI fragment of pMP74 containing the downstream region was cloned in pMP73, which was digested with the same enzymes. In the resulting plasmid pMP77, the upstream and downstream regions were ligated at the BamHI restriction site. This site was used to introduce a Km-resistance cassette between the two regions, resulting in pMP85. The construct containing the upstream and downstream regions with the Km-resistance cassette was recovered by cutting with XhoI-SpeI restriction enzymes and was cloned in plasmid pRK290 (Ditta et al. 1980) at the EcoRI restriction site, yielding pMP86. This plasmid was conjugally transferred from Escherichia coli to Bradyrhizobium japonicum wild-type strain by triparental mating using the helper plasmid pRK2013 (Ditta et al. 1980). The bat/bto operon was specifically replaced by the Km-resistance cassette as a consequence of the homologous recombination between the upstream and downstream regions present on the chromosome and on pMP86, respectively.

Southern hybridization was performed to confirm the replacement of bat/bto genes with the Km-resistance cassette. A 1,351-bp HindIII-SalI fragment carrying the Km-resistance cassette was hybridized to the BamHI-digested total DNA of the mutant and wild-type strains to prove the presence of the selectable marker in the mutant. Furthermore, the presence of the resistance cassette and the absence of the bat/bto module were also detected by PCR. Primer pairs were designed; in each case, one of the primers was specific for the neighboring genomic region (BAT-UP-F, 5'-ATGGCCGAGGAAGGGATA G-3' and BTO-DW-R, 5'-ACCATGCACCTTCCTGATTT-3' for the upstream and downstream regions, respectively), whereas the other one was specific for the Km cassette (KM-R, 5'-GG CTTCCCAACCTTACCAG-3' and KM-F, 5'-TCGGCATCCA GGAAACCA-3'). Using the corresponding primer pairs (BATUP-F and KM-R, KM-F and BTO-DW-R), amplified fragments of correct sizes were detected from the total DNA of the mutant strain, demonstrating that the resistance cassette replaced specifically the bat/bto module. Finally, by sequencing of the upstream and downstream regions amplified from the total DNA of the mutant strain by using BAT-1 BAT-2 and
BAT-3 BAT-4, respectively, no further changes were revealed in the neighboring regions at DNA sequence level.

Construction of the complemented strain MP120. In order to confirm that the pleiotropic effects observed in the phenotype of MP99 are all due to the deletion of the bat/bto operon, a complemented strain, MP120, was constructed. Primers BATPR-F (5'-TCAAACAGACGCATCCCCCGG-3') and BAT104-R (5'-AGATAGGGCTATGGGTCGTC-3') were used to amplify a fragment consisting of the coding sequence of the bat/bto operon and 248 bp upstream of the translation start site of the operon. The amplicon was cloned into the EcoRI restriction site of plasmid pRK290 (resulting in the plasmid pMP117) and was introduced into B. japonicum MP99 mutant strain by triparental mating, yielding the MP120 complemented strain.

Construction of the revertant strain MP119. To avoid any possible unwanted effect of multiple copies present in the complemented strain, in another experiment, a revertant strain (MP119) was constructed. A DNA fragment containing the bat/bto genes and a 1-kb upstream and 1.2-kb downstream region of the operon was amplified by PCR using the primers BAT1 and BAT4. This fragment was cloned in the EcoRI restriction site of plasmid pRK290. The resulting plasmid pMP118 was conjugally transferred from $E$. coli to MP99 strain by triparental mating, and the bat/bto region was inserted into the chromosome by double homologous recombination. The presence of the wild-type bat/bto genes was confirmed by Southern hybridization using as probe a PCR fragment amplified by the BAT1.2 (5'-TCACAACACT GCACCCGAC-3') and BAT2.1 (5'-GCCGAATGCAGCGAA ATCC-3') primers. This fragment covers a 677-bp region of the $b a t / b t o$ operon.

Plasmid containing the promoter region of the bat/bto operon. To determine the expression of the bat/bto operon, a 379-bp fragment consisting of the 233-bp intergenic region, 144 and 2 bp of the $g l p D$ and bat/bto coding regions, respectively, was amplified with primers BAT1 and BAT2 and was digested with BamHI-SalI restriction enzymes. The promoter-containing fragment was filled by Klenow polymerase and was inserted into plasmid pEP82 (Élö et al. 1998) upstream of the promoterless lac $Z$ gene. The resulting plasmid pMP105 was introduced into wild-type, mutant, and complemented B. japonicum strains by conjugation.

Plasmids carrying bat, bto, or the bat/bto operon under the IPTG-inducible promoter of pET-28b. To investigate the effect of the ectopic expression of the bat/bto module in E. coli cells, plasmids containing bat, bto, or bat/bto genes were constructed by cloning the appropriate PCR fragments first in pBluescriptII digested with SmaI. The following plasmids were obtained: pMP108 carrying the bat gene amplified by the primers B101F (5'CTTGCTGCCATGGCCATCA-3') and B102-R (5'-AGC AGGTTCACGGCATCT- $\left.3^{\prime}\right)$, pMP110 carrying the bto gene amplified by the primers B103-F (5'-CGACGAGATGCCATG GACCT-3') and B104-R (5'-AGATAGGGCTATGGGTCGCT$\left.3^{\prime}\right)$, and pMP111 carrying the entire bat/bto operon amplified by the primers B101-F and B104-R.

The pBluescriptII derivatives containing the cloned fragments were digested with $N c o$ I (present on the fragment) and SalI (present on the multicloning site of the vector), and the inserts were recloned in the NcoI-SalI-digested pET-28b vector (Merck, Darmstadt, Germany). The plasmids carrying the bat (pMP112), bto (pMP113), or bat/bto (pMP114) genes under the T7-inducible promoter were transformed in $E$. coli BL21-Gold (DE3) competent cells. Thus, the NcoI restriction site of pET-28b and the translational start codon ATG were restored in the plasmids, due to the presence of an NcoI site in the sequence of forward primers (underlined). 
Viability tests.

E. coli BL21-Gold (DE3) cells with plasmids pMP112, pMP113, pMP114, or the vector pET-28b were grown overnight in LB medium supplemented with $\mathrm{Km}$. The cultures were diluted in the same medium to obtain equal optical densities $\left(\mathrm{OD}_{600}=0.1\right)$ and were induced with $1 \mathrm{mM}$ IPTG. Cultures were grown at $37^{\circ} \mathrm{C}$, and samples were removed to determine $\mathrm{OD}$ and viable cell number.

\section{RT-PCR.}

RNA was extracted from cells at logarithmic phase using the RNA Easy mini kit from Qiagen (Hilden, Germany). Reverse transcription was performed from identical amounts $(1 \mu \mathrm{g})$ of RNA obtained from wild-type, MP99, and MP120 strains using the Transcription First Strand cDNA synthesis kit (Roche Applied Science, Indianapolis, IN, U.S.A.). RT-PCR was performed with identical volumes of cDNA samples as templates, using specific primers for the following genes: hisS (HIS1, 5'GAGATGGTCGAGAAGATCC-3' and HIS2, 5'-ATCGTAAC GCAAGCTAATC-3'), pmtA (PTA1, 5'-CTTCGTCCAGTTCA CCTAT- $3^{\prime}$ and PTA2, 5'-TTAATCCTTGCGATACACC-3') and pmtX1 (PTX1, 5'-GGTCTACGATCTCGTGTT-3' and PTX2, 5'-AGAGCACCTCGACATTGC-3'). Controls without the reverse transcriptase enzyme or without the template cDNA were also performed. All experiments were repeated three times.

\section{AFM.}

Bacteria were grown at $31^{\circ} \mathrm{C}$ in YEM medium. Aliquots were removed from the cultures at early logarithmic phase and were washed with PBS. To immobilize the cells, muscovite mica surface was coated with a $0.1 \%$ (wt/vol) solution of poly-Llysine (molecular weight $>300,000$ ) for at least $2 \mathrm{~h}$. Bacterial adhesion was carried out at room temperature by depositing 20 $\mu \mathrm{l}$ of bacterial suspension onto mica surface, was buffered at $\mathrm{pH} \mathrm{7,} \mathrm{and} \mathrm{was} \mathrm{incubated} \mathrm{for} 20 \mathrm{~min}$. The sample holder containing bacteria was filled with distilled water during experiments.

AFM measurements were carried out with an Asylum MFP3D head and controller (Asylum Research, Santa Barbara, CA, U.S.A.) in AC mode. The driver program MFP-3D Xop was written in IGOR Pro software (version 5.05b; Wavemetrics, Lake Oswego, OR, U.S.A.). Silicon nitride cantilevers (BioLever Mini BL-AC40TS; Olympus Optical Co., Ltd., Tokyo) with a nominal spring constant of $90 \mathrm{pN} / \mathrm{nm}$ were used. Typically $512 \times 512$-pixel scans were taken at a scan rate of 0.3 to 1.0 lines per second under water. Both trace and retrace images were measured and compared for accuracy, no difference was found between them. A number of at least 40 cells were subjected to the measurements.

To characterize the changes in the mechanical properties of membranes, the elastic (Young's) modulus was determined by force measurements as was described earlier (Balint et al. 2007; Wilhelm et al. 2007), except that force curves were recorded at a constant speed of $600 \mathrm{~nm} \mathrm{~s}^{-1}$. All experiments were repeated at least four times.

\section{Detection of LPS.}

Bacterial cultures of B. japonicum wild-type, MP99, and MP120 strains were grown in liquid PSY medium. Cultures $(200 \mu \mathrm{l})$ of logarithmic phase were pelleted by centrifugation and were washed and extracted with the hot phenol-water method (Kiss et al. 1997). The aqueous phases were pooled and exhaustively dialyzed (membrane cutoff 6,000 to 8,000 $\mathrm{kDa}$ ) against water. This crude polysaccharide solution was lyophilized and then dissolved in $100 \mu \mathrm{l}$ of water.

Total polysaccharide extracts were analyzed by sodium deoxycholate-polyacrylamide gel elecrophoresis, using $18 \%$ poly- acrylamide gels with deoxycholic acid as detergent (Krauss et al. 1988). Equal amounts of polysaccharide extracts were loaded on gels, except when otherwise described. Sample buffer, gel electrophoresis buffer, and silver staining were used as described by Krauss and associates (1988). Experiments were performed three times.

\section{Lipid extraction.}

Cells grown in PSY medium $(50 \mathrm{ml})$ were harvested at $\mathrm{OD}_{600}=0.8$ and were washed twice with PBS, and the wet bacterial cell paste was subjected to lipid extraction procedure according to a modified Bligh and Dyer method (Kates 1986). The final dried lipid extract was immediately dissolved in 300 $\mu \mathrm{l}$ of chloroform/methanol $(2: 1)$ and was stored at $-20^{\circ} \mathrm{C}$.

\section{Fatty-acid analysis of total lipid extracts.}

Lipid samples $(50 \mu \mathrm{l})$ were dried in ampules and transmethylated with $2 \mathrm{ml}$ of $5 \%$ acetyl chloride (in methanol) at $80^{\circ} \mathrm{C}$ for $2 \mathrm{~h}$. The resulting fatty-acid methyl esters (FAME) were extracted with hexane, the solvent was evaporated, and the residue was dissolved in $50 \mu \mathrm{l}$ of benzene and was analyzed using the Shimadzu GC-MS-QP2010 (Shimadzu Corporation, Tokyo) equipped with a BPX70 capillary column $(10 \mathrm{~m}$ $\times 0.1 \mathrm{~mm} \times 0.2 \mu \mathrm{m})($ SGE Analytical Science Pty Ltd., Ringwood, Australia). A 1- $\mu$ l aliquot was injected onto the column maintained at $150^{\circ} \mathrm{C}$ for $2 \mathrm{~min}$ and programmed at $6^{\circ} \mathrm{C}$ per minute from 150 to $215^{\circ} \mathrm{C}$ and at $20^{\circ} \mathrm{C}$ per minute to $235^{\circ} \mathrm{C}$ and then maintained isothermally for $2 \mathrm{~min}$. Fatty-acid composition is given as weight percent $(\%)$ of total. The measurements were made in triplicate.

\section{Separation of individual PL.}

Individual lipid classes were separated by thin-layer chromatography on Kielselgel 60 silica gel TLC plates (Merck \& Co., Inc., Whitehouse Station, NJ. U.S.A.) First, a developing solvent of acetone/petroleum ether $\left(30\right.$ to $\left.50^{\circ} \mathrm{C}, 1: 3\right)$ was used to run to the top of the plate, which was then dried. Second, a chloroform/methanol/acetic acid (65:25:10) solvent was run for $2 / 3$ of the plate. Lipids were visualized by spraying the plate with $0.05 \%$ 8-anilinonaphtalene-1-sulfonate in methanol and were identified using authentic standards. Depending on the relative fluorescence, 0.5 to $5 \mu \mathrm{g}$ of C24:0 fatty acid was applied on the spots as internal standards. The spots were scraped off the plate and transmethylated, and FAME was analyzed as above. All measurements were done in triplicate.

\section{$\beta$-galactosidase measurements.}

B. japonicum strains grown at $31^{\circ} \mathrm{C}$ in PSY medium containing the appropriate antibiotics were diluted to $\mathrm{OD}_{600}=0.1$ and were further cultivated to $\mathrm{OD}_{600}=0.5$. The $\beta$-galactosidase activity was determined as described previously (Oláh et al. 2001). Glycerol was added to the tested medium when required at a final concentration of $0.04 \%$. Measurements were repeated five times.

\section{Symbiotic interaction with soybean host plant.}

Soybean seeds (Glycine max var. Pannonia Kincse) were surface-sterilized, were germinated for 3 days at room temperature, and then, were placed in pots containing clay beads (Lodeiro and Favelukes 1999). Aliquots (1 ml) of B. japonicum wild-type or MP99 mutant cultures grown in PSY medium were used at the logarithmic growth phase $\left(\mathrm{OD}_{600}=0.6\right.$; $6.7 \times 10^{8}$ and $7.3 \times 10^{8}$ cells per milliliter, respectively) for inoculation of each plant. For both bacterial strains, 30 soybean plants were analyzed. After 60 days, plants were harvested, and the number of nodules and the dry weight of shoots were determined. To analyze nodule occupancy, 40 nodules were 
randomly collected from plants inoculated either by the wildtype or by the MP99 mutant strain and were surface-sterilized by repeated washing with $96 \%$ ethanol and, finally, with sterile distilled water. The nodules were crushed and suspended in $0.9 \% \mathrm{NaCl}$, and 40 to $80 \mu \mathrm{l}$ of the solution was placed on YEM agar plates. A total of 200 colonies from each strain type were checked for Km resistance to select for the MP99 mutant strain and for spectinomycin to select for the wild-type strain.

\section{Databases and software.}

The complete genomic sequence of Bradyrhizobium japonicum was available online at the Kazusa Research Institute RhizoBase website and the BacMap Genome Atlas site. Sequence analyses were done using the ClustalW2 Bioedit program and Promscan.

\section{ACKNOWLEDGMENTS}

The authors would like to thank E. Fejes for critical reading of the manuscript. We thank É. Dobó for excellent technical assistance. This work was supported by the Bástyai-Holczer Fund, the Hungarian National Scientific Research Foundation T048706 for G. Váró and 68379 for I. Horváth.

\section{LITERATURE CITED}

Alting-Mees, M. A., and Short, J. M. 1989. pBluescript II: Gene mapping vectors. Nucleic Acids Res. 17:9494.

Amitai, S., Yassin, Y., and Engelberg-Kulka, H. 2004. MazF-mediated cell death in Escherichia coli: A point of no return. J. Bacteriol. 186:82958300.

Arcus, V. L., Backbro, K., Roos, A., Daniel, E. L., and Baker, E. N. 2004. Distant structural homology leads to the functional characterization of an archaeal PIN domain as an exonuclease. J. Biol. Chem. 279:1647116478.

Bálint, Z., Krizbai, I. A., Wilhelm, I., Farkas, A. E., Pardutz, A., Szegletes, Z., and Varo, G. 2007. Changes induced by hyperosmotic mannitol in cerebral endothelial cells: An atomic force microscopic study. Eur. Biophys. J. 36:113-120.

Bodogai, M., Ferenczi, S., Bashtovyy, D., Miclea, P., Papp, P., and Dusha, I. 2006. The ntrPR operon of Sinorhizobium meliloti is organized and functions as a toxin-antitoxin module. Mol. Plant-Microbe Interact. 19:811-822.

Boncompagni, E., Osteras, M., Poggi, M. C., and Le Rudulier, D. 1999. Occurrence of choline and glycine betaine uptake and metabolism in the family Rhizobiaceae and their roles in osmoprotection. Appl. Environ. Microbiol. 65:2072-2077.

Brooun, A., Liu, S., and Lewis, K. 2000. A dose-response study of antibiotic resistance in Pseudomonas aeruginosa biofilms. Antimicrob. Agents Chemother. 44:640-646.

Bunker, R. D., McKenzie, J. L., Baker, E. N., and Arcus, V. L. 2008. Crystal structure of PAE0151 from Pyrobaculum aerophilum, a PIN-domain (VapC) protein from a toxin-antitoxin operon. Proteins 72:510-518.

Buts, L., Lah, J., Dao-Thi, M. H., Wyns, L., and Loris, R. 2005. Toxinantitoxin modules as bacterial metabolic stress managers. Trends Biochem. Sci. 30:672-679.

Carrion, M., Bhat, U. R., Rheus, B., and Carlson, R. W. 1990. Isolation and characterization of the lipopolysaccharides from Bradyrhizobium japonicum. J. Bacteriol. 172:1725-1731.

Christensen, S. K., Mikkelsen, M., Pedersen, K., and Gerdes, K. 2001. RelE, a global inhibitor of translation, is activated during nutritional stress. Proc. Natl. Acad. Sci. U.S.A. 98:14328-14333.

Danilova, L. V., Gelfand, M. S., Lyubetsky, V. A., and Laikova, O. N. 2003. Computer-assisted analysis of regulation of the glycerol-3phosphate metabolism in genomes of Proteobacteria. Mol. Biol. 37:716-722.

Dénarié, J., Debellé, F., and Promé, J.-C. 1996. Rhizobium lipochitooligosaccharide nodulation factors: Signaling molecules mediating recognition and morphogenesis. Annu. Rev. Biochem. 65:503-535.

Ditta, G., Stanfield, S., Corbin, D., and Helinski, D. R. 1980. Broad host range DNA cloning system for gram-negative bacteria: Construction of a gene bank of Rhizobium meliloti. Proc. Natl. Acad. Sci. U.S.A. 77:7347-7351.

Donegan, N. P., and Cheung, A. L. 2009. Regulation of the mazEF toxinantitoxin module in Staphylococcus aureus and its impact on $\operatorname{sig} B$ expression. J. Bacteriol. 191:2795-2805.
Élö, P., Semsey, S., Kereszt, A., Nagy, T., Papp, P., and Orosz, L. 1998. Integrative promoter cloning plasmid vectors for Rhizobium meliloti. FEMS (Fed. Eur. Microbiol. Soc.) Microbiol. Lett. 159:7-13.

Gerdes, K. 2000. Toxin-antitoxin molecules may regulate synthesis of macromolecules during nutritional stress. J. Bacteriol. 182:561-572.

Gerdes, K., Christensen, S. K., and Lobner-Olesen, A. 2005. Prokaryotic toxin-antitoxin stress response loci. Nat. Rev. Microbiol. 3:371-382.

Gibson, K. E., Kobayashi, H., and Walker, G. C.2008. Molecular determinants of a symbiotic chronic infection. Annu. Rev. Genet. 42:413-41.

Guerinot, M. L., Meidl, E. J., and Plessner, O. 1990. Citrate as a siderophore in Bradyrhizobium japonicum. J. Bacteriol. 172:3298-3303.

Hacker, S., Sohlenkamp, C., Aktas, M., Geiger, O., and Narberhaus, F. 2008. Multiple phospholipid $N$-methyltransferases with distinct substrate specificities are encoded in Bradyrhizobium japonicum. J. Bacteriol. 190:571-580.

Hahn, M., and Hennecke, H. 1984. Localized mutagenesis in Rhizobium japonicum. Mol. Gen. Genet. 193:46-52.

Hayes, F. 2003. Toxins-antitoxins: Plasmid maintenance, programmed cell death and cell cycle arrest. Science. 301:1496-1499.

Hazan, R., Sat, B., and Engelberg-Kulka, H. 2004. Escherichia coli $m a z E F$-mediated cell death is triggered by various stressful conditions. J. Bacteriol. 186:3663-3669.

Horváth, I., Mansourian, A. R., Vigh, L., Thomas, P. G., Joó, F., and Quinn, P. J. 1986. Homogeneous catalytic hydrogenation of the polar lipids of pea chloroplasts in situ and the effects on lipid polymorphism. Chem. Phys. Lipids 39:251-264.

Jensen, R. B., and Gerdes, K. 1995. Programmed cell death in bacteria: Proteic plasmid stabilization systems. Mol. Microbiol. 17:205-210.

Jones, K. M., Kobayashi, H., Davies, B. W., Taga, M. E., and Walker, G. C. 2007. How rhizobial symbionts invade plants: The SinorhizobiumMedicago model. Nat. Rev. 5:619-633.

Jørgensen, M. G., Pandey, D. P., Jaskolska, M., and Gerdes, K. 2009. HicA of Escherichia coli defines a novel family of translation-independent mRNA interferases in bacteria and archaea. J. Bacteriol. 191:11911199.

Kates, M. 1986. Techniques in lipidology. Pages 232-254 in: Isolation and Identification of Lipids, 2nd ed. R. H. Burdon, P. H. van Knippenberg, eds. Elsevier, Amsterdam.

Keren, I., Shah, D., Spoering, A., Kaldalu, N., and Lewis, K. 2004. Specialized persister cells and the mechanism of multidrug tolerance in Escherichia coli. J. Bacteriol. 186:8172-8180.

Kiss E, Reuhs, B. L., Kim, J. S., Kereszt, A., Petrovics, G., Putnoky, P., Dusha, I., Carlson, R. W., and Kondorosi, A. 1997. The rkpGHI and -J genes are involved in capsular polysaccharide production by Rhizobium meliloti. J. Bacteriol. 179:2132-2140.

Korch, S. B., Contreras, H., and Clark-Curtiss, J. E. 2009. Three Mycobacterium tuberculosis Rel toxin-antitoxin modules inhibit mycobacterial growth and are expressed in infected human macrophages. J. Bacteriol. 191:1618-1630.

Krauss, J. H., Weckesser, J., and Mayer, H. 1988. Electrophoretic analysis of lipopolysaccharides of purple nonsulfur bacteria. Int. J. Syst. Bacteriol. 38:157-163.

Lehnherr, H., Magnuson, R., Jafri, S., and Yarmolinsky, M. B. 1993. Plasmid addiction genes of bacteriophage $\mathrm{P} 1$ : doc, which causes cell death on curing of prophage, and phd, which prevents host death when prophage is retained. J. Mol. Biol. 233:414-428.

Lodeiro, A. R., and Favelukes, G. 1999. Early interactions of Bradyrhizobium japonicum and soybean roots: Specificity in the process of adsorption. Soil Biol. Biochem. 31:1405-1411.

Lewis, K. 2005. Persister cells and the riddle of biofilm survival. Biochemistry-Moscow 70:267-274.

Magnuson, R., and Yarmolinsky, M. B. 1998. Corepression of the P1 addiction operon by Phd and Doc. J. Bacteriol. 180:6342-6351.

Makarova, K. S., Aravind, L., Galperin, M. Y., Grishin, N. V., Tatusov, R. L., Wolf, Y. I., and Koonin, E. V. 1999. Comparative genomics of the Archaea (Euryarchaeota): Evolution of conserved protein families, the stable core, and the variable shell. Genome Res. 9:608-628.

Maniatis, T., Fritsch, E. F., and Sambrook, J. E. 1982. Molecular Cloning. A laboratory Manual. Cold Spring Harbor Laboratory, Cold Spring Harbor, NY, U.S.A.

Marianovsky, I., Aizenman, E., Engelberg-Kulka, H., and Glaser, G. 2001 The regulation of the Escherichia coli mazEF promoter involves an un usual alternating palindrome. J. Biol. Chem. 276:5975-5984.

Martínez-Morales, F., Schobert, M., López-Lara I. M., and Geiger O. 2003. Pathways for phosphatidylcholine biosynthesis in bacteria. Microbiology 149:3461-3471.

Mattison, K., Wilbur, J. C., So, M., and Brennan, R. G. 2006. Structure of FitAB from Neisseria gonorrhoeae bound to DNA reveals a tetramer of toxin-antitoxin heterodimers containing PIN domains and ribbon-helixhelix motifs. J. Biol. Chem. 281:37942-37951. 
Mileykovskaya, E., and Dowhan, W. 2005. Role of membrane lipids in bacterial division-site selection. Curr. Opin. Microbiol. 8:135-142.

Mine, N., Guglielmini, J., Wilbaux, M., and Van Melderen, M. 2009. The decay of the chromosomally encoded $c c d_{\mathrm{O} 157}$ toxin-antitoxin system in the Escherichia coli species. Genetics, 181:1557-1566.

Oláh, B., Kiss, E., Györgypál, Z., Borzi, J., Cinege, G., Csanádi, G., Batut, J., Kondorosi, A., and Dusha, I. 2001. Mutation in the ntrR gene, a member of the vap gene family, increases the symbiotic efficiency of Sinorhizobium meliloti. Mol. Plant-Microbe Interact. 14:887894.

Pandey, D. P., and Gerdes, K. 2005. Toxin-antitoxin loci are highly abundant in free-living but lost from host-associated prokaryotes. Nucleic Acids Res. 33:966-976.

Pedersen, K., Christensen, S. K., and Gerdes, K. 2002. Rapid induction and reversal of a bacteriostatic condition by controlled expression of toxins and antitoxins. Mol. Microbiol. 45:501-510.

Pedersen, K., Zavialov, A. V., Pavlov, M. Y., Elf, J., Gerdes, K., and Ehrenberg, M. 2003. The bacterial toxin RelE displays codon-specific cleavage of mRNAs in the ribosomal A site. Cell. 112:131-140.

Puskás, L. G., Nagy, Z. B., Kelemen, J. Z., Rüberg, S., Bodogai, M., Becker, A., and Dusha, I. 2004. Wide-range transcriptional modulating effect of $n t r R$ under microaerobiosis in Sinorhizobium meliloti. Mol. Gen. Genomics 272:275-289.

Regensburger, B., and Hennecke, H. 1983. RNA polymerase from Rhizobium japonicum. Arch. Microbiol. 135:103-109.

Rietveld, A. G., Killian, J. A, Dowhan, W., and de Kruijff, B. 1993. Polymorphic regulation of membrane phospholipid composition in Escherichia coli. J. Biol. Chem. 15:12427-33.

Sat, B., Hazan, R., Fisher, T., Khaner, H., Glaser, G., and EngelbergKulka, H. 2001. Programmed cell death in Escherichia coli: Some antibiotics can trigger mazEF lethality. J. Bacteriol. 183:2041-2045.

Smith, J. A., and Magnuson, R. D. 2004. Modular organization of the Phd repressor/antitoxin protein. J. Bacteriol. 186:2692-2698.

Stacey, G., So, J. S., Roth, L. E., Lakshmi, S. K. B., and Carlson, R. W. 1991. A lipopolysaccharide mutant of Bradyrhizobium japonicum that uncouples plant from bacterial differentiation. Mol. Plant-Microbe Interact. 4:332-340
Tsilibaris, V., Maenhaut-Michel, G., Mine, N., and Van Melderen, L. 2007. What is the benefit of Escherichia coli of having multiple toxin-antitoxin systems in its genome? J. Bacteriol. 189:6101-6108.

Vigh, L., Escribá, P. V, Sonnleitner, A., Sonnleitner, M., Piotto, S., Maresca, B., Horváth I., and John L. Harwood. 2005. The significance of lipid composition for membrane activity: New concepts and ways of assessing function. Progr. Lipid. Res. 44:303-344.

Vincent, J. M. 1970. A manual for the practical study of root nodule bacteria. International Biological Program Handbook 15. Blackwell Scientific Publications, Oxford.

Wilhelm, I., Farkas, A. E., Nagyöszi, P., Váró, G., Bálint, Z., Végh, G. A., Couraud, P-O., Romero, I. A., Weksler, B., and Krizbai, I. A. 2007. Regulation of cerebral endothelial cell morphology by extracellular calcium. Phys. Med. Biol. 52:6261-6274.

Yang, B., and Larson, T. J. 1996. Action at a distance for negative control of transcription of the $g l p D$ gene encoding sn-glycerol 3-phosphate dehydrogenase of Escherichia coli K-12. J. Bacteriol. 178:70907098 .

Yang, B., and Larson, T. J. 1998. Multiple promoters are responsible for transcription of the glpEGR operon of Escherichia coli K-12. Biochim. Biophys. Acta 1396:114-126.

Ye, S. Z., and Larson, T. J. 1988. Structures of the promoter and operator of the $g l p D$ gene encoding aerobic sn-glycerol-3-phosphate dehydrogenase of Escherichia coli K-12. J. Bacteriol. 170:4209-4215.

Zhang, Y., Zhang, J., Hoeflich, K. P., Ikura, M., Qing, G., and Inouye, M. 2003. MazF cleaves cellular mRNAs specifically at ACA to block protein synthesis in Escherichia coli. Mol. Cell 12:913-923.

\section{AUTHOR-RECOMMENDED INTERNET RESOURCES}

BacMap Genome Atlas: wishart.biology.ualberta.ca/BacMap European Molecular Biology Laboratory-European Bioinformatics Institute ClustalW2 website: www.ebi.ac.uk/Tools/clustalw2/index.html

Kazusa Research Institute RhizoBase webpage: bacteria.kazusa.or.jp/rhizobase

Queen's University's Promscan: molbiol-tools.ca/promscan 